\title{
A comparative study of certain pharmacological effects of lidocaine and ropivacaine
}

\author{
Premendran John, BenHur Premendran*, Jayasree T, Siresha J V, Karunakar \\ Kota,Venkateshwarlu P,Vijay Kalwa, Vijay Sharma* \\ Department of Pharmacology, Mamata Medical College, Khammam 507002, Andhra Pradesh, India. \\ *Department of Anaesthesiology, Mahatma Gandhi Institute of Institute of Medical Sciences, Sewagram \\ 442102, Maharashtra State, India.
}

\begin{abstract}
In order to study the safety and efficacy of lidocaine and ropivacaine some of their actions were compared using the parameters namely local anaesthetic effect on rabbit cornea, local anaesthetic effect on the reflex movements of the nostrils of rabbit, analgesic effect on rat, cardiac effect on frog heart and the effect on the blood vessels of frog.

The local anaesthetic effect on rabbit cornea and reflex movements of the nostrils of rabbit had longer duration with ropivacaine but there were differences in the onset of action.

By rat tail flick method, ropivacaine proved to be more potent and longer acting in its analgesic action.

Ropivacaine took longer time to produce bradycardia. There was less number of missed beats of the frog heart with ropivacaine.

While lidocaine produced vasoconstriction of frog blood vessels, ropivacaine produced initial vasoconstriction followed by vasodilatation.

In all the parameters used, ropivacaine proved to be more potent, longer acting and safer when compared to lidocaine.
\end{abstract}

Keywords - Lidocaine,ropivacaine,local anaesthetic effect, analgesic effect, bradycardia,vasoconstriction.

\section{INTRODUCTION}

Though the pharmacological effects of lidocaine and ropivacaine are well established individually, there are conflicting reports of the comparison of actions between these two drugs both experimentally and clinically (Raffi Kapitanyan 2010). While lidocaine is a well established local anaesthetic, ropivacaine is a new aminoamide local anaesthetic agent with a greater margin of safety than other local anaesthetics for cardio toxicity and central nervous system toxicity(McClure J H, 1996; Knudsen K, et al, 1997). Hence, it was thought to further explore experimentally certain pharmacological actions of these drugs and try to assess the safety and efficacy of the two drugs to be helpful for further experimental and clinical studies to establish safe use of lidocaine and ropivacaine.

Materials and Methods:

The parameters used for this study were the local anaesthetic effect on the rabbit cornea, the local anaesthetic effect on the reflex movements of the nostrils in rabbit, analgesic effect on the rat, cardiac effect on the frog heart, and the effect on the blood vessels of frog.

The experiment was approved by the Institutional Animal Ethics Committee, Mamata Medical College, Khammam, Andhra Pradesh, India. Pharmacy.

Lidocaine and ropivacaine (Neon Laboratories Ltd, Mumbai) were procured from Institution's

Animals used in these experiments were male Wister albino rats weighing 150-180 g, albino rabbits weighing $1.5 \mathrm{Kg}$, and frogs purchased from the Institutional breeding stock. The animals were housed at $25 \pm 2^{\circ} \mathrm{C}$ in clean polypropylene cages. They had access to food and water ad libitum throughout the duration of the study. All efforts were made to minimise both the suffering and the number of animals used.

1. Local anaesthetic effect on corneal reflex in rabbits (Yao-Tseng Huang, et al 1946):

The object of the study was to demonstrate and compare the local anaesthetic effect of lidocaine and ropivacaine on rabbit by corneal reflex method. The method described by Yao-Tseng Huang (1946) was followed with slight modification. Three groups of rabbits with five animals in each group were taken. The first

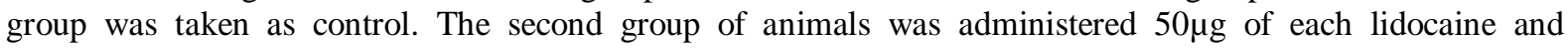


ropivacaine by injecting into the limbus of the left eye and right eye respectively. The second and third groups were given $100 \mu \mathrm{g}$ and $200 \mu \mathrm{g}$ each of lidocaine and ropivacaine respectively by the same route of administration. The local anaesthetic effect was studied before and after the administration of the drugs by eliciting the corneal reflex with the help of a pointed cotton swab. The onset of action was noted when the corneal reflex was lost and the duration of action was noted when the corneal reflex was recovered.

\section{Local anaesthetic effect on the reflex movements of nostrils in rabbist:}

A modified Regniers method was followed, introduced by Hotovy in 1956 (Hans G Vogels, 2007). This method also helps in demonstrating and comparing the local anaesthetic effect of lidocaine and ropivacaine. This involves the absence and presence of movements of the nostrils in rabbit by the use of the test drug. The first group was kept as control.

The second group was administered $2.5 \mu \mathrm{g}$ of lidocaine and ropivacaine by injecting the drug into the mucosa of any one of the nostrils on separate animals. The third group was administered $5 \mu \mathrm{g}$ of lidocaine and ropivacaine by injecting the drugs by the method mentioned above. The local anaesthetic effect was studied by testing the reflex movements of nostrils when stimulated by using a fine tipped pencil. The onset of action was noted when the movement of nostrils due to stimulation was absent after injecting the test drug. The duration of action was noted when reflex was regained.

\section{Analgesic effect on albino rats by tail-flick method (D'Amour F E, et al, 1941):}

The object of the study was to demonstrate and compare the analgesic effect of lidocaine and ropivacaine on albino-rats by tail-flick method (D'Amour F E, and Smith D L, 1941). Six groups of animals, with six animals in each group were taken. The first, second, and third groups were administered $6.25 \mu \mathrm{g}, 12-25$ $\mu \mathrm{g}$, and $25 \mu \mathrm{g}$ of lidocaine subcutaneously, respectively near the base of the tail. The fourth, fifth, and sixth groups were administered $6.25 \mu \mathrm{g}, 12.5 \mu \mathrm{g}$, and $25 \mu \mathrm{g}$ of ropivacaine subcutaneously, respectively. The analgesic effect was studied by noting the tail-retaining time on the analgesiometer, ie, the absence of tail-flick was taken as the start of analgesic effect. Each animal was tested for the tail-flick before administering the test drugs, which served as the control. The duration of action was noted as the tail-flick was regained.

\section{Cardiac effect on the frog heart:}

The object of the study was to demonstrate and compare the cardiac toxic effect of lidocaine and ropivacaine using frog heart perfusion (G K Pal and Pravati Pal-I, 2005). Twelve groups of frogs with 3 animals in each group were used. In group one, after taking the normal graph of the myocardial contractions $6.25 \mu \mathrm{g}$ lidocaine was added to $500 \mathrm{ml}$ of perfusing Ringer and the perfusion was continued. In group two, the same method was followed as in group one but with a dose of $12.5 \mu \mathrm{g}$ lidocaine. In group three, with the same method, $25 \mu \mathrm{g}$ of lidocaine was used. In group four, five, and six, the same method was used as in group one but lidocaine was replaced with ropivacaine in the doses of $6 \mu \mathrm{g}, 12.5 \mu \mathrm{g}$, and $25 \mu \mathrm{g}$ respectively.

\section{Effect on the blood vessels of frog (S S Gambhir, et al 1970):}

The object of the study was to demonstrate and compare the vasoconstrictor or vasodilatory effect of lidocaine and ropivacaine. The method described by G K Pal and Pravati Pal-II (2005) was followed with slight modification. The aorta was cannulated after cutting off a major portion of the ventricle. Through the cannulation the perfusion of the vessels of the body of the animal was started as the fluid passed from the reservoir. The perfusion rate was established by counting drops falling in the i.v. set used for perfusing the blood vessels. Reduction in the number of drops indicated vasoconstriction and increase in the number of drops indicated vasodilatation.

\section{RESULTS}

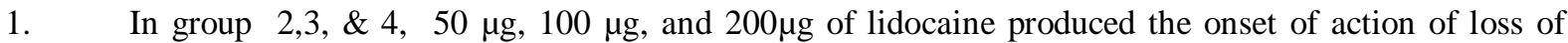
corneal reflex in $11.6 \mathrm{~min}, 10.8 \mathrm{~min}$, and $8 \mathrm{~min}$ respectively. $50 \mu \mathrm{g}, 100 \mu \mathrm{g}$, and $200 \mu \mathrm{g}$ of ropivacaine produced the onset of action of loss of corneal reflex in $2 \mathrm{~min}, 2 \mathrm{~min}$, and $1 \mathrm{~min}$ respectively (Table 1; Fig.1). $50 \mu \mathrm{g}, 100$ $\mu \mathrm{g}$, and $200 \mu \mathrm{g}$ of lidocaine produced the duration of action of regain of corneal reflex in $12.4 \mathrm{~min}, 22.8 \mathrm{~min}$, and 40.0min respectively(Table 2; Fig.2). Again $50 \mu \mathrm{g}, 100 \mu \mathrm{g}, 200 \mu \mathrm{g}$ of ropivacaine produced the duration of action of regain of corneal reflex in 26.0min, 38.4min, and 80.0min respectively(Table.2; Fig.2).

Table 1: Effects of Lidocaine and Ropivacaine on corneal reflex in rabbits

\begin{tabular}{|l|l|l|l|}
\hline \multirow{2}{*}{ Drug } & \multicolumn{3}{|l|}{ Onset of Action in minutes in different doses } \\
\cline { 2 - 4 } & $50 \mathrm{mg}$ & $100 \mathrm{mg}$ & $200 \mathrm{mg}$ \\
\hline Lidocaine & $11.6 \pm 0.74$ & $10.8 \pm 0.48$ & $8.4 \pm 0.4$ \\
\hline Ropivacaine & 2.0 & 2.0 & 1.0 \\
\hline P-value & 0.00 & 0.00 & 0.00 \\
\hline
\end{tabular}

All values are expressed as Mean \pm SD 


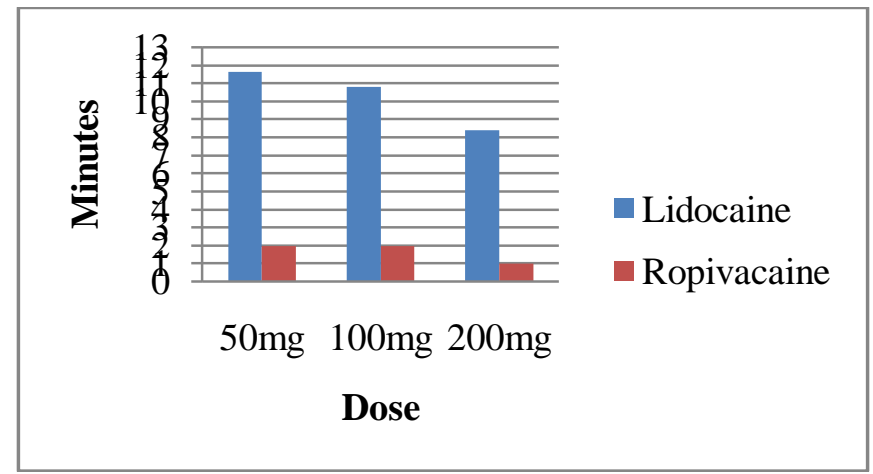

Fig 1: Comparison of onset of Action of Lidocaine and Ropivacaine on corneal reflex in rabbits Table 2: Effects of Lidocaine and Ropivacaine on corneal reflex in rabbits

\begin{tabular}{|l|l|l|l|}
\hline \multirow{2}{*}{ Drug } & \multicolumn{3}{|l|}{ Duration of Action in minutes in different doses } \\
\cline { 2 - 4 } & $50 \mathrm{mg}$ & $100 \mathrm{mg}$ & $200 \mathrm{mg}$ \\
\hline Lidocaine & $12.4 \pm 1.16$ & $22.8 \pm 0.8$ & $40.4 \pm 0.4$ \\
\hline Ropivacaine & $26.0 \pm 1.09$ & $38.4 \pm 0.4$ & $80.0 \pm 0.63$ \\
\hline P-value & 0.00 & 0.00 & 0.00 \\
\hline
\end{tabular}

All values are expressed as Mean \pm SD

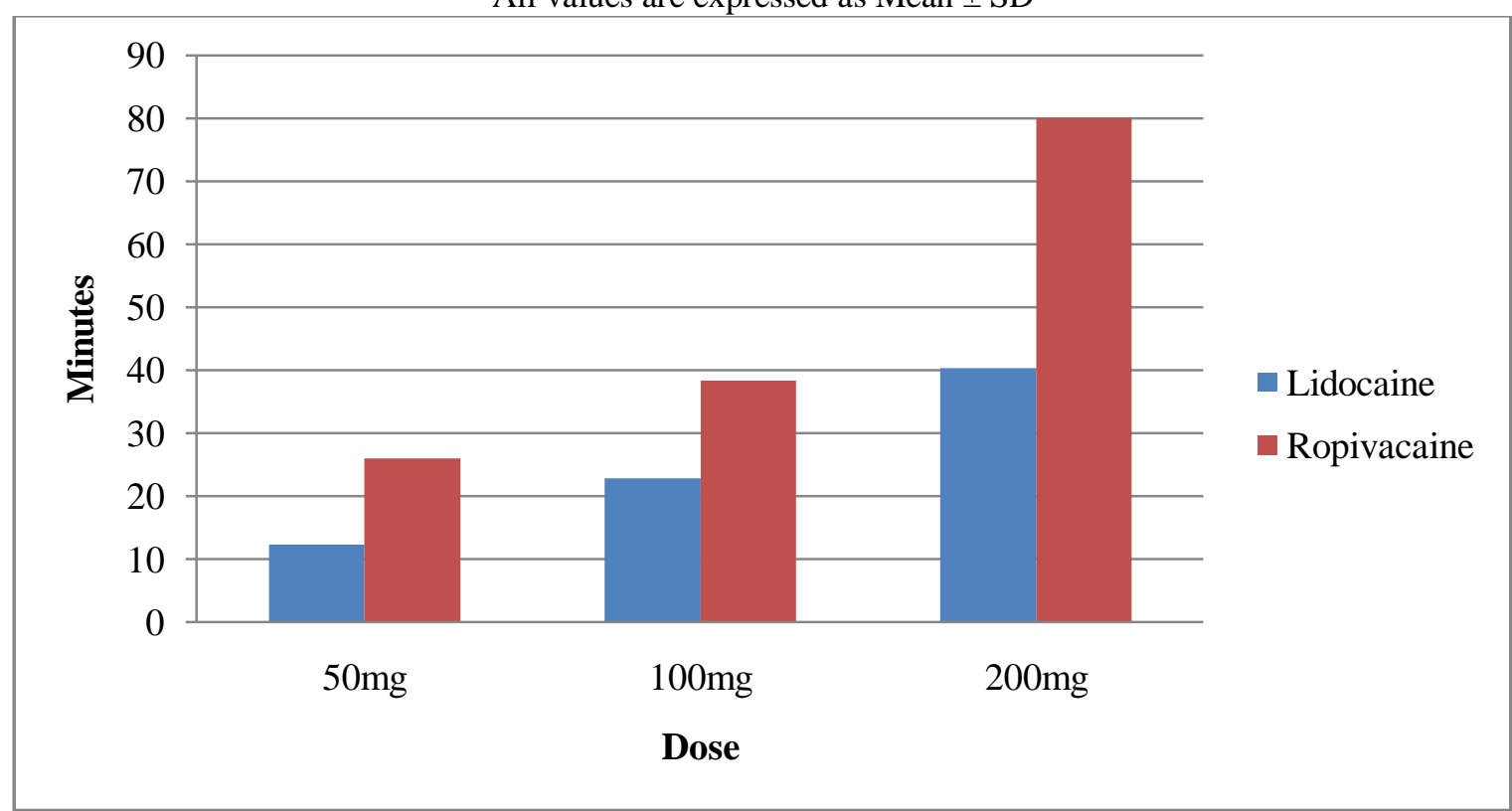

Fig 2: Comparison of duration of Action of Lidocaine and Ropivacaine on corneal reflex in rabbits

2. In groups 2 and 3, $2.5 \mu \mathrm{g}$ and $5.0 \mu \mathrm{g}$ of lidocaine produced the onset of action of loss of movement of nostrils in $11.0 \mathrm{~min}$, and $20.0 \mathrm{~min}$ respectively. $2.5 \mu \mathrm{g}$ and $5.0 \mu \mathrm{g}$ of ropivacaine produced the onset of action of loss of movement of nostrils in 17.0min, and 38.0min respectively(Table 3; Fig.3). In groups 2 and 3, $2.5 \mu \mathrm{g}$ and $5.0 \mu \mathrm{g}$ of lidocaine produced the duration of action of regain of movements of nostrils in $45.0 \mathrm{~min}$ and $94.0 \mathrm{~min}$ respectively. $2.5 \mu \mathrm{g}$ and $5.0 \mu \mathrm{g}$ of ropivacaine produced the duration of action of regain of movement of nostrils in 80.0min and 163.0min respectively(Table 4; Fig.4).

Table 3: Effect of Lidocaine and Ropivacaine on the reflex movements of nostrils in rabbits

\begin{tabular}{|l|l|l|}
\hline \multirow{2}{*}{} & Onset of Action in minutes in different doses \\
\cline { 2 - 3 } & $2.5 \mu \mathrm{g}$ & $5.0 \mu \mathrm{g}$ \\
\hline Lidocaine & $11.0 \pm 1.21 \mathrm{~min}$ & $20.0 \pm 2.99 \mathrm{~min}$ \\
\hline Ropivacaine & $17.0 \pm 1.21 \mathrm{~min}$ & $38.0 \pm 2.82 \mathrm{~min}$ \\
\hline P-value & $<0.0001$ & $<0.0001$ \\
\hline
\end{tabular}

All values are expressed as Mean \pm SD value

-8 - 
A comparative study of certain pharmacological effects of lidocaine and ropivacaine

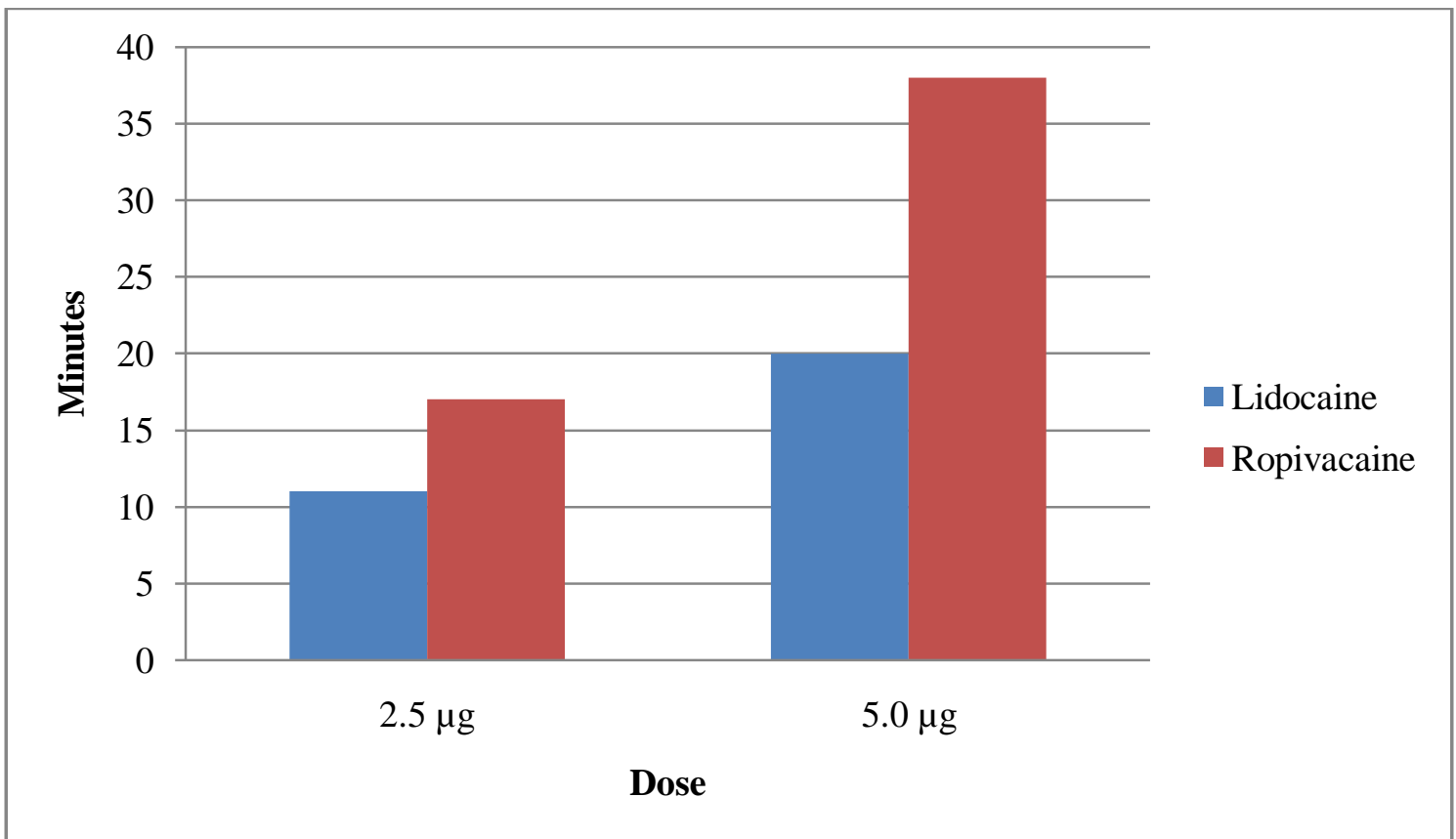

Fig 3: Comparison of onset of action of Lidocaine and Ropivacaine on the reflex movements of nostrils in rabbits

Table 4: Effect of Lidocaine and Ropivacaine on the reflex movements of nostrils in rabbits

\begin{tabular}{|l|l|l|}
\hline \multirow{2}{*}{ Drug } & Duration of Action in different doses \\
\cline { 2 - 3 } & $2.5 \mu \mathrm{g}$ & $5.0 \mu \mathrm{g}$ \\
\hline Lidocaine & $45.0 \pm 2.73 \mathrm{~min}$ & $94.0 \pm 6.28 \mathrm{~min}$ \\
\hline Ropivacaine & $80.0 \pm 4.32 \mathrm{~min}$ & $163.0 \pm 4.91 \mathrm{~min}$ \\
\hline P-value & $<0.0001$ & $<0.0001$ \\
\hline
\end{tabular}

All values are expressed as Mean \pm SD value

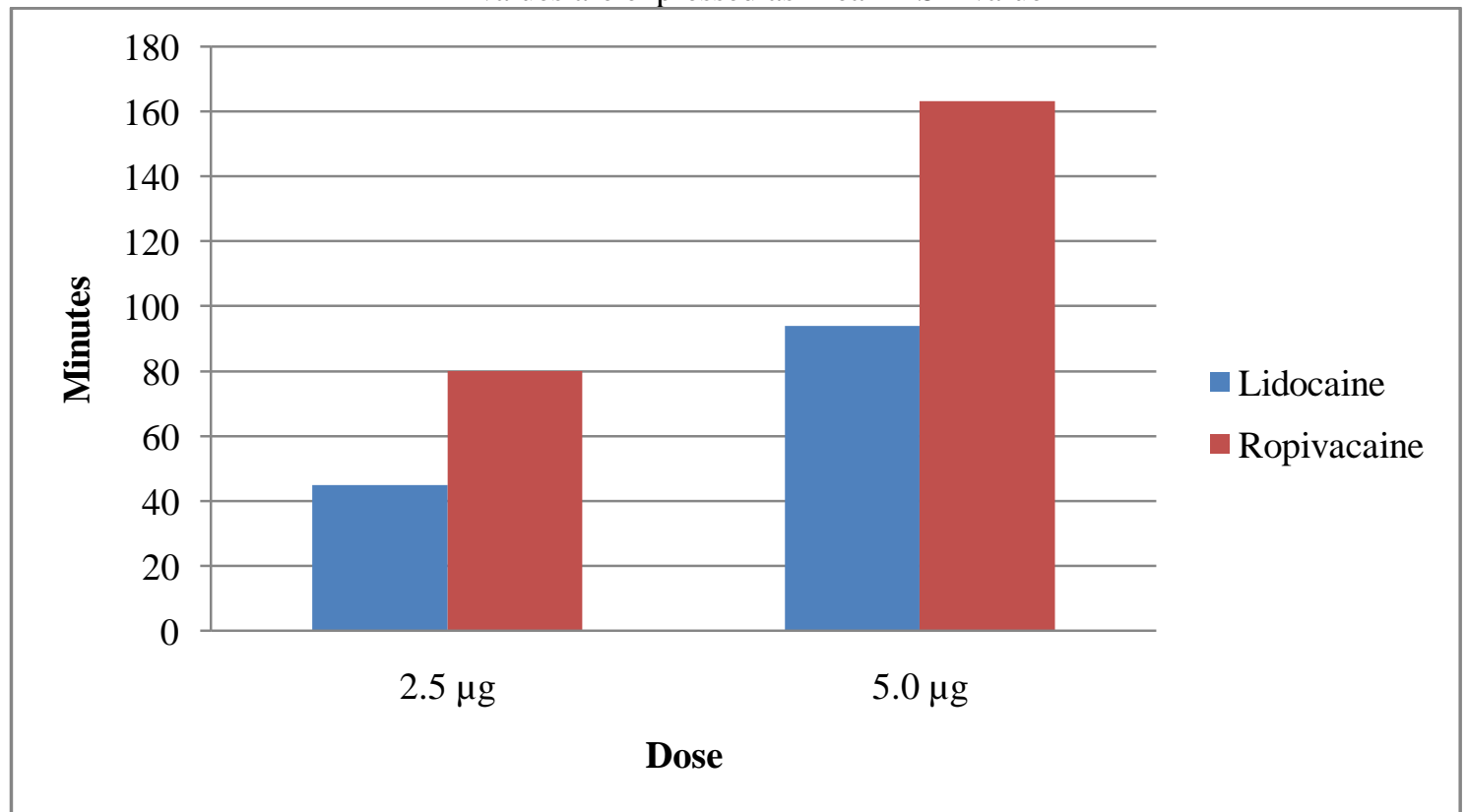

Fig 4: Comparison of duration of action of Lidocaine and Ropivacaine on the reflex movements of nostrils in rabbits

3. In group 1, where $6.25 \mu \mathrm{g}$ of lidocaine was added the onset of action was reduced to $2.25 \mathrm{~min}$ and $1.5 \mathrm{~min}$ respectively. In group 4 , where $6.25 \mu \mathrm{g}, 12.5 \mu \mathrm{g}$, and $25.0 \mu \mathrm{g}$ of ropivacaine were added, the onset of action was uniformly the same with $3 \mathrm{~min}$ for all the three doses(Table 5; Fig.5). In group 1, where $6.25 \mu \mathrm{g}$, $12.5 \mu \mathrm{g}$, and $25.0 \mu \mathrm{g}$ of lidocaine were added, the durations of action of action were $60.0 \mathrm{~min}, 80.0 \mathrm{~min}$, and 
A comparative study of certain pharmacological effects of lidocaine and ropivacaine

120.0min respectively. In group 4, where $6.25 \mu \mathrm{g}, 12.5 \mu \mathrm{g}$, and $25.0 \mu \mathrm{g}$ of ropivacaine were added the durations of action were $145 \mathrm{~min}, 175 \mathrm{~min}$, and $210 \mathrm{~min}$ respectively(Table 6; Fig.6).

Table 5: Analgesic effect of Lidocaine and Ropivacaine on rats by tail-flick method

\begin{tabular}{|l|l|l|l|}
\hline Onset of action in minutes & 12.5 & 25.0 \\
\hline Dose (in mcg) & 6.25 & $2.33 \pm 0.51$ & $1.41 \pm 0.49$ \\
\hline Lidocaine & $4.33 \pm 1.03$ & $3.0 \pm 0.0$ & $3.0 \pm 0.0$ \\
\hline Ropivacaine & $3.0 \pm 0.0$ & $<0.01$ & 0.00 \\
\hline P-value & 0.00 &
\end{tabular}

All values are expressed as Mean \pm SD value

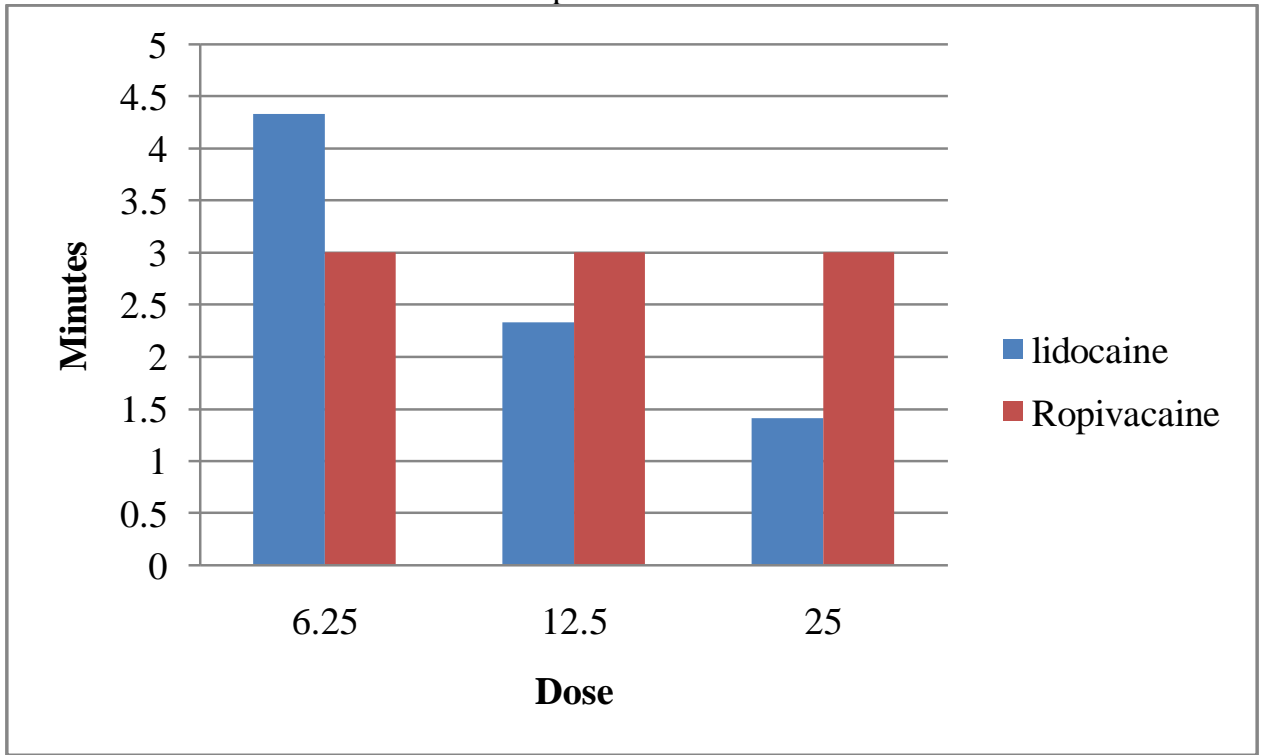

Fig 5: Comparison of onset of analgesic effect of Lidocaine and Ropivacaine on rats by tail-flick method Table 6: Analgesic effect of Lidocaine and Ropivacaine on rats by tail-flick method

\begin{tabular}{|l|l|l|l|}
\hline \multicolumn{4}{|l|}{ Duration of action in minutes } \\
\hline Dose (in mcg) & 6.25 & 12.5 & 25.0 \\
\hline Lidocaine & $55.67 \pm 1.03$ & $86.17 \pm 2.56$ & $118.4 \pm 0.66$ \\
\hline Ropivacaine & $147.0 \pm 0.0$ & $177.0 \pm 0.0$ & $207.0 \pm 0.0$ \\
\hline P-value & 0.00 & 0.00 & 0.00 \\
\hline
\end{tabular}

All values are expressed as Mean \pm SD value

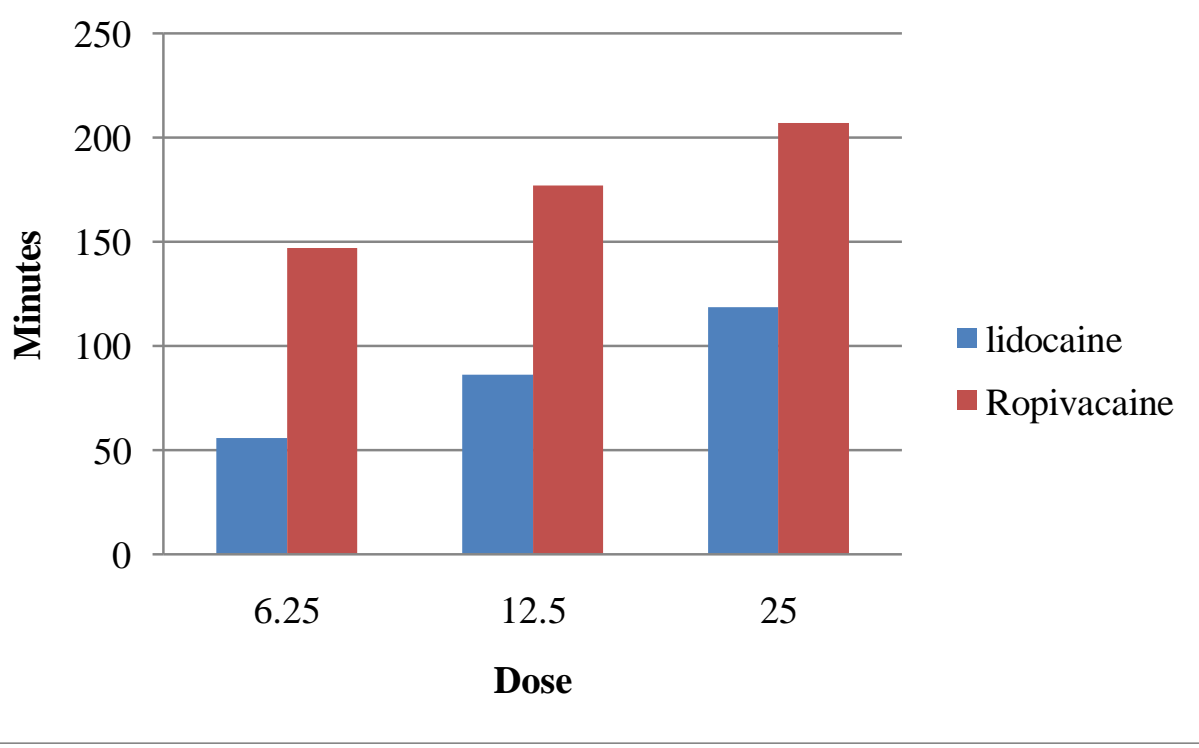

Fig 6: Comparison of duration of analgesic effect of Lidocaine and Ropivacaine on rats by tail-flick method 
A comparative study of certain pharmacological effects of lidocaine and ropivacaine

4. On perfused frog heart, lidocaine reduced the force of contraction progressively when the drug was added to the perfusion fluid in increased doses. There was also bradycardia, and the heart stopped in systolic arrest. When compared to lidocaine ropivacaine increased the force of contraction initially with bradycardia but the cardiac arrest was produced one and half times later than that of lidocaine. The missed beats were less for ropivacaine when compared to lidocaine(Table 7; Fig.7).

Table 7: Effect of Lidocaine and Ropivacaine on perfused frog heart

\begin{tabular}{|l|l|l|l|l|l|l|}
\hline \multicolumn{6}{|l|}{ Number of heart beats / min } \\
\hline Dose & $0.4 \mathrm{mcg}$ & $0.8 \mathrm{mcg}$ & $1.68 \mathrm{mcg}$ & $3.36 \mathrm{mcg}$ & $6.72 \mathrm{mcg}$ & $13.4 \mathrm{mcg}$ \\
\hline Control & 50.66 & 56.33 & 44.0 & 30.7 & 37.5 & 44.66 \\
\hline Lidocaine & 34.03 & 24.13 & 31.39 & 21.67 & 21.24 & 24.58 \\
\hline Ropivacaine & 42.16 & 37.73 & 37.93 & 25.21 & 34.64 & 32.95 \\
\hline
\end{tabular}

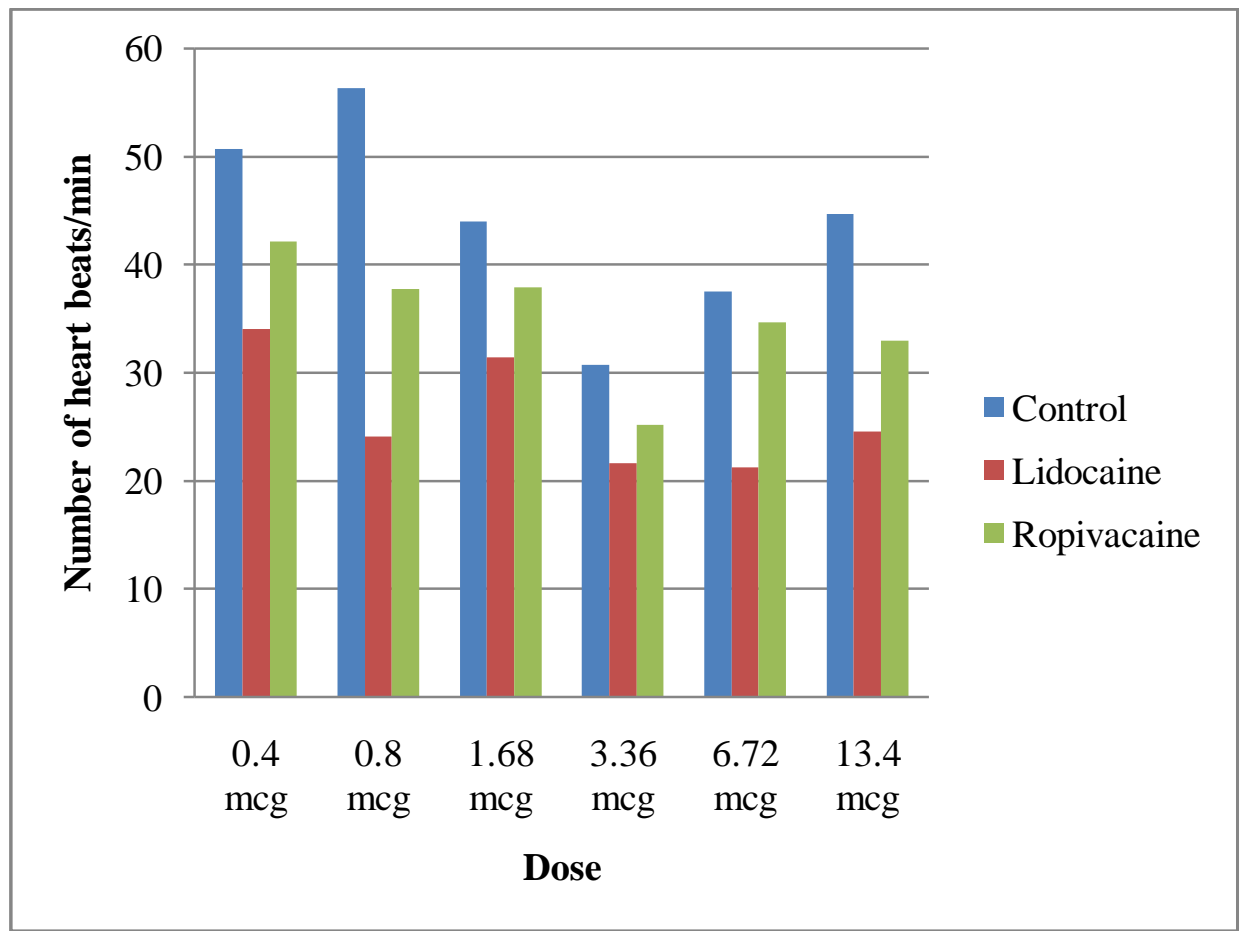

Fig 7: Comparison of toxicity of Lidocaine and Ropivacaine on perfused frog heart

5. On perfused blood vessels of frog, lidocaine produced vasoconstriction. Ropivacaine produced lesser initial vasoconstriction followed by vasodilation(Table 8; Fig.8).

Table 8: Effect of Lidocaine and Ropivacaine on the perfused blood vessels of frog

\begin{tabular}{|l|l|l|l|l|}
\hline & \multicolumn{2}{l|}{} \\
\hline Dose & $6.72 \mathrm{mcg}$ & $13.44 \mathrm{mcg}$ & $26.88 \mathrm{mcg}$ & $53.76 \mathrm{mcg}$ \\
\hline Control & 113.12 & 102.66 & 82.16 & 56.0 \\
\hline Lidocaine & 81.51 & 85.42 & 75.33 & 17.24 \\
\hline Ropivacaine & 96.74 & 118.86 & 129.98 & 79.51 \\
\hline
\end{tabular}


A comparative study of certain pharmacological effects of lidocaine and ropivacaine

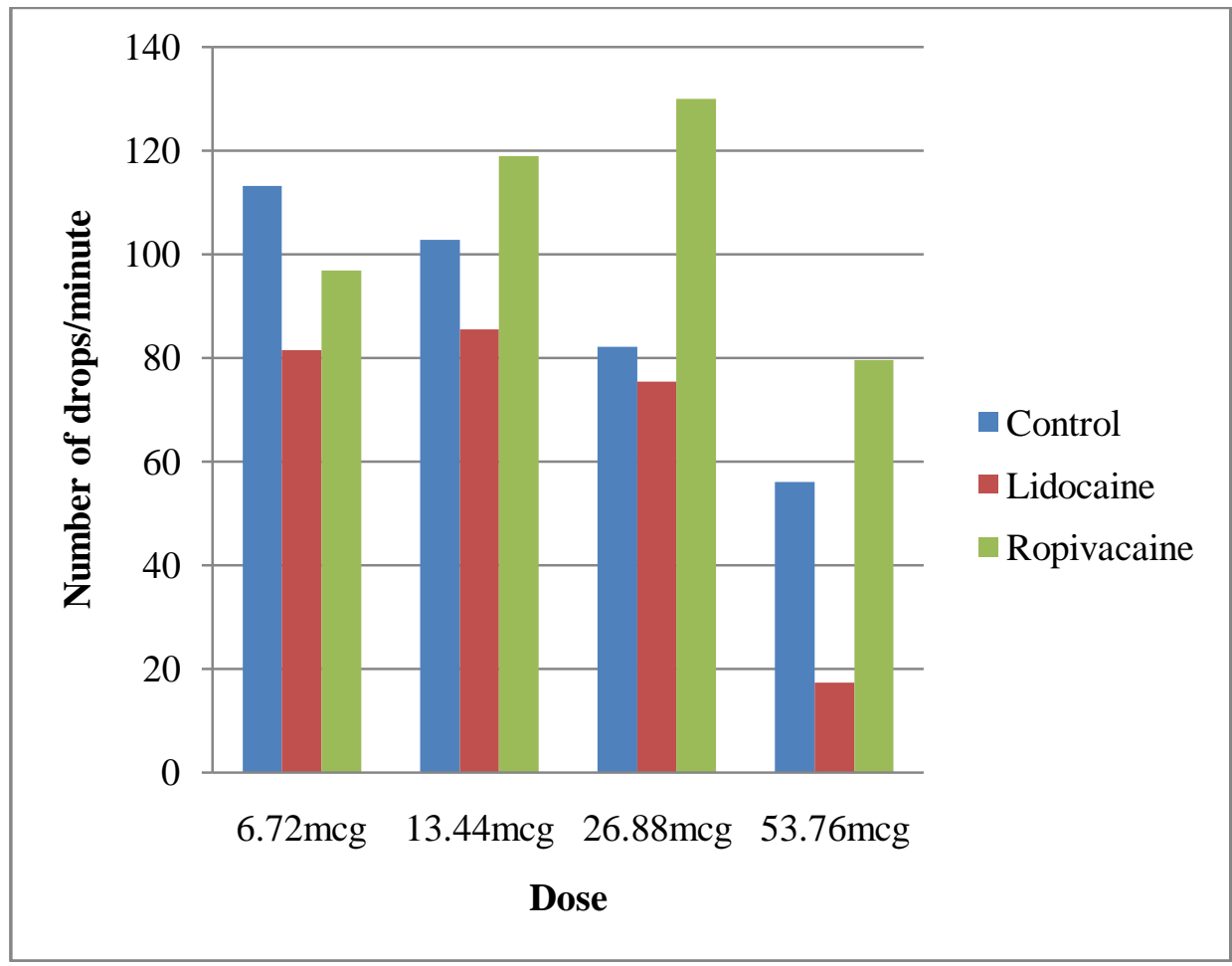

Fig 8: Comparison of Lidocaine and Ropivacaine on the perfused blood vessels of frog For all parameters used, the observations were statistically significant as shown in the respective tables.

\section{DISCUSSION}

1. In the rabbit corneal reflex experiments the onset of action for ropivacaine was earlier than that of lidocaine in the same doses of $50 \mu \mathrm{g}, 100 \mu \mathrm{g}$, and $200 \mu \mathrm{g}$. Similarly, the duration of action of ropivacaine was twice longer than lidocaine in the same doses. Both the results were statistically significant. Nicholson, et al (2000) has stated that lidocaine produces faster onset of action than ropivacaine, in contrast to our observation. However, it should be noted that they had used different concentrations of lidocaine $(2 \%)$ and ropivacaine $(1 \%)$. But we used the same concentrations of both the local anaesthetics. This may be the reason for the faster onset of ropivacaine. The findings of Borazan, et al (2007) also coincide with our results regarding the longer duration of action of ropivacaine than lidocaine.

They claim that long acting local anaesthetics like ropivacaine can be used safely in order to provide topical anaesthesia in cataract surgery and to avoid the necessity for repeated instillation doses.

2. In the other study of local anaesthetic effect of lidocaine and ropivacaine on the reflex movement of nostrils in rabbit, we got different results regarding the onset of action of lidocaine and ropivacaine when compared to the results of rabbit corneal reflex experiments. In spite of the same doses given for both the local anaesthetics, lidocaine yet produced faster onset of action when compared to ropivacaine. Though the species of animal used was same, the difference in the tissue/organ used might be the cause for the different results (Borazan, et al 2007). And yet, there was no difference in results regarding the duration of action of lidocaine and ropivacaine on the reflex movements of the nostrils in rabbits. Ropivacaine still produced twice the duration of time when compared to lidocaine in different doses.

3. In the comparative study of the analgesic action of lidocaine and ropivacaine on rats by tail flick method, ropivacaine proved to be more potent and longer acting in its analgesic action when compared to lidocaine. Ropivacaine increased the duration of action in both low dose and high dose. Peng Philip, et al (2002) have also made similar observations in their experiments in humans.

4. In comparing the effects of lidocaine and ropivacaine on the perfused frog heart ropivacaine took a longer time in producing bradycardia and finally the cardiac arrest in systole. The force of myocardial contraction by ropivacaine was greater than lidocaine. The missed beats produced by ropivacaine were less in number when compared to lidocaine. This observation is supported by the reports of Gheradini, et al (1995).

5. On the perfused blood vessels of frog lidocaine produced vasoconstriction. On the other hand ropivacaine produced initial vasoconstriction followed by vasodilatation. This observation is also supported by 
the findings of Gherardini et al (1995). Hence, if it is true in case of humans, use of ropivacaine may require the addition of adrenaline in order to avoid systemic adverse effects when high doses are given.

\section{CONCLUSION}

Our study using different parameters clearly demonstrates that ropivacaine has rapid onset and longer duration of action; it is more potent but less cardiotoxic and produces delayed vascular effects when compared to lidocaine (Mc Claure J H, 1996; Knudson K, et al 1997).

\section{REFERENCES}

[1]. Raffi Kapitanyan and Asim Tarabar.Toxicity, Local Anaesthetics.Medscape Reference - Drugs, Disease \& Procedures (2010) - http://emedicine.medscape.com/article/184455 - overview.

[2]. Yao-Tseng Huang, Ming-Cheng Lu, and I-Chang.Local anaesthesia - rabbit eye method.The synthesis, toxicity, and anaesthetic potency of two new local anaesthetics.Brit. J. Pharmacol (1946),1, 273

[3]. Hans G. Vogel, Hans G. Vogel.Drug Discovery and Evaluation Pharmacological Assays. Method introduced by Hotovy in 1956 using Regniers method - ostrils.www.books.google.co.in/books.(2007).

[4]. D'Amour F E, and Smith D L.Tail flick method - A method for determining loss of pain sensation.J. Pharmacol.exp.Ther. 71, 74-79 (1941).

[5]. G. K. Pal and Pravati Pal.Frog Heart Perfusion. Text Book of Practical Physiology, $2^{\text {nd }}$ Ed.

[6]. Orient Longman Pvt.Ltd. 2005, 406-7.

[7]. $\quad$ S S Ghambhir and P K Das.Frog Blood Vessels Perfusion Method. Q.Jl.Exp.Physiol. (1970) 55, 313-319 Frog Blood Vessels Perfusion Method.Text Book of Practical Physiology, $2^{\text {nd }}$ Ed.Orient Longman Pvt.Ltd. 2005. 408-9.

[8]. G Nicholson, B Sutton, and G M Hall.Comparison of $1 \%$ ropivacaine with $0.75 \%$ bupivacaine and $2 \%$ lidocaine for peribulbar anaesthesia.British Journal of Anaesthesia 84(1):89-91 (2000).

[9]. M Borazan, A Karalezli, Y A Akova, C Algan and S Oto.Comparative clinical trial of topical anaesthetic agents for cataract surgery withphacoemulsification: lidocaine $2 \%$ drops, levobupicacaine $0.75 \%$ drops, and ropivacaine $1 \%$ drops.Eye (2008) 22, 425-429

[10]. Peng Philip, Colman MM, McCartney CJ, Krone S, Chan VW, Kaszas Z, Vucelilo I. Comparative anaesthetic effect between $0.375 \%$ ropivacaine versus $0.5 \%$ lidocaine in forearm intravenous regional anaesthesia.Regional Anaesthesia and Pain Medicine 2002, vol.27 issue 6, 595-599.

[11]. Kermidas, Evangelos, Rondopoulov, Stavroula.Ropivacaine vs lidocaine in digital nerve blocks: A prospective study.Journal of American Society of Plastic Surgeons.2007- vol.119, issue 7, 2148-2152.

[12]. G Gerardini, samuelson U, Jembeck J, Aberq B, Sjastrand N Comparison of vascular effects of ropivacaine and lidocaine on isolated rings of human arteries. Acta Anaesthsiol Scand. Vol.39, issue 6, 265-268, 1995.

[13]. McClure J H. Ropivacaine.Br. J Anaesth 1996; 76:300-7.

[14]. Knudsen K, Beckman M, Blomberg S, Sjovall J, Edvardsson N.Central nervous and cardiovascular effects of i.v. infusions of ropivacaine, bupivacaine and placebo in volunteers.Br. J Anaesth 1997; 78:507-14 